Check for updates

Cite this: RSC Adv., 2019, 9, 15686

Received 29th January 2019

Accepted 29th April 2019

DOI: 10.1039/c9ra00783k

rsc.li/rsc-advances

\section{Determination and distribution of pesticides and antibiotics in agricultural soils from northern China $\uparrow$}

\author{
Lixiang Pan, ${ }^{a}$ Xiaoxiao Feng, ${ }^{a}$ Meng Cao, ${ }^{b}$ Shiwen Zhang, ${ }^{c}$ Yuanfang Huang, ${ }^{b}$ \\ Tianheng $\mathrm{Xu}^{\mathrm{a}}{ }^{\mathrm{a}}$ Jing Jing $^{\mathrm{a}}$ and Hongyan Zhang ${ }^{\mathrm{D}}$ *a
}

Different types of soil samples from a typical farmland in northern China were collected and evaluated for the presence of the pesticides and antibiotics. 47 pesticides were extracted with a quick, easy, cheap, effective, rugged, and safe (QuEChERS) preparation method and cleanup with $50 \mathrm{mg} \mathrm{C}_{18}$, while 10 antibiotics were extracted with methanol/EDTA-Mcllvaine buffer solution ( $v / v=1 / 1$ ), then both of them were analyzed with high performance liquid chromatography-tandem mass spectrometer (HPLC-MS/ MS). Total concentrations of the 47 pesticides in the soil samples ranged from not detectable (ND) to $3.8 \mathrm{mg} \mathrm{kg}^{-1}$. The soil exhibited relatively high ecological risk for atrazine, chlorpyrifos, tebuconazole, difenoconazole, pymetrozine, and thiamethoxam, as over $1.0 \%$ of the sample concentrations exceeded $0.1 \mathrm{mg} \mathrm{kg} \mathrm{kg}^{-1}$. The residual levels of the 10 antibiotics were relatively low (ND-951.0 $\mu \mathrm{g} \mathrm{kg}^{-1}$ ). Tetracyclines exhibited a high detection rate $(20.9 \%)$, with $2.8 \%$ of the soil samples exhibiting tetracyclines concentrations exceeding $100 \mu \mathrm{g} \mathrm{kg}^{-1}$, implying high ecological risk. The 4 sulfonamides and 2 macrolides analyzed showed detection rates below $0.8 \%$. Spatial changes in the distribution of pesticides and antibiotics appear to be related to land use patterns, particularly orchards and vegetable plots. The over-standard rate of pesticides and antibiotics in orchards was greater than that of vegetable plots, and grain fields had the lowest over-standard rate. These data were helpful to figure out the pollution of these pesticides and antibiotics, and provided valuable information for soil quality assessment and risk assessment.

\section{Introduction}

Soil is an integral part of the environment and ecosystem. It is an important natural resource for plant growth, and is also a repository for the material biogeochemical cycle. It has a high sensitivity to environmental changes, ${ }^{1}$ and is often the predominant sink for environmental pollution due to its strong binding capacity. ${ }^{2}$ Furthermore, soil is also a secondary emission source of organic pollutants because of reequilibration among various bulk media., "Soil pollution" is defined as the presence of chemicals or substances in the soil that are inappropriate and/or at a higher concentration than normal, with adverse effects for any non-target creature. ${ }^{5}$ Controlling soil pollution is important because soil quality is

${ }^{a}$ College of Science, China Agricultural University, Beijing, 100193, P. R. China. E-mail: hongyan@cau.edu.cn

${ }^{b}$ College of Resources and Environmental Sciences, China Agricultural University, Beijing, 100193, P. R. China

${ }^{c}$ College of Earth and Environmental Sciences, Anhui University of Science and Technology, Huainan, Anhui province, 232001, P. R. China

$\dagger$ Electronic supplementary information (ESI) available. See DOI: $10.1039 / \mathrm{c} 9 \mathrm{ra} 00783 \mathrm{k}$ directly related to food safety, human health, and sustainable economic and social development. ${ }^{6,7}$ The Status of the World's Soil Resources Report (SWSR) identified soil pollution as a major threat affecting global soils and the ecosystems services that they provide. $^{8}$ It is estimated that there are approximately 80000 contaminated soil sites in Australia, and that are listed in the Superfund National Priorities List., ${ }^{5,9}$ In 2014, the Chinese Environmental Protection Ministry released a survey bulletin on the state of soil pollution in the country, which revealed that $16.1 \%$ of all Chinese soil was polluted, including $19.4 \%$ of farmland. ${ }^{10}$

Pesticides and antibiotics play major roles in agriculture and livestock production, and their use has been increasing globally in recent years. ${ }^{\mathbf{1} 11}$ China produces more pesticides and antibiotics than any other country, and irrational use or even abuse occurs frequently. ${ }^{12-14}$ Due to the lack of timely degradation, the persistence of pesticides and antibiotics in soil has caused a series of environmental issues, including ecological risks and damage to human health. ${ }^{15-18}$ In addition, residual antibiotics in the soil can promote the spread of antibiotic resistance and trigger adverse immunological reactions. ${ }^{19}$ Agricultural soil pollution from pesticides and approximately 1300 locations in the United States of America 
antibiotics is a challenging problem that needs to be fully addressed. The results of some studies indicate that a new QuEChERS (quick, easy, cheap, effective, rugged and safe) technique shows more popular than other extraction techniques at the multi-residue extraction of pesticides from soil matrices. ${ }^{\mathbf{2 0 - 2 2}}$ However, for the detection of multi-residue antibiotics in soil, buffer salt extraction and solid phase extraction (SPE) purification are the most common methods. ${ }^{15,23}$ Gas chromatography and liquid chromatography combined with various detectors can analyze the broadest spectrum of compounds, thereinto, high performance liquid chromatography-tandem mass spectrometry (HPLC-MS/MS) methods based on triple quadrupole (QqQ) analyzers are frequently used in environmental and food analysis. ${ }^{21,24,25}$ However, few reports have been published to date that simultaneously focus on contamination from both pesticides and antibiotics in the environment. ${ }^{\mathbf{1 , 2 6 - 2 8}}$ The analysis methods in these studies are cumbersome and require relatively large manpower, material resources and financial resources. Because the number of samples analyzed in these studies were relatively less, and their contingencies were too large to accurately reflect the pollution situation in a particular region. Furthermore, to our best to know, there is no published report that focuses on contamination from pesticides and antibiotics in different agricultural soil types.

The soil samples used in this study were collected in one of China's major production areas for agricultural and sideline products, lied between Beijing and Tianjin. The purpose of this study is to determine the concentration, distribution, and risk of pollution of pesticides and antibiotics in different types of farmland soils. Soil quality standards have not yet been established for various pesticides and antibiotics. Therefore, this study is very important for understanding the risk of agricultural soil pollution, and will help in developing effective remediation strategies. It also could provide basic data for the establishment of relevant soil quality standards in China.

\section{Materials and methods}

\subsection{Study sites and sampling}

An intensive and large-scale soil-sampling program was conducted, during which a total of 530 soil samples were collected. The study area is located from $116^{\circ} 55^{\prime} \mathrm{E}-117^{\circ} 24^{\prime} \mathrm{E}$, and from $40^{\circ} 10^{\prime} \mathrm{N}-40^{\circ} 22^{\prime} \mathrm{N}$, and the location of each sampling site is provided in Fig. 1. ArcGIS software was used to acquire and mesh the spatial distribution of the orchards and vegetable fields in the study area. The mesh distribution was designed according to the control area and the principle of stratified sampling. The orchard grid size was $235 \times 235 \mathrm{~m}$, while the vegetable grid size was $160 \times 160 \mathrm{~m}$. A Global Positioning System (GPS) was used to accurately record each location, based on the sampling map and the coordinate position of the plot. According to the size and shape of the sampling plots, a random sample of 10 samples was taken following either the plum blossom method, snake method, or chessboard method. Each sample was taken from a depth of 0 -

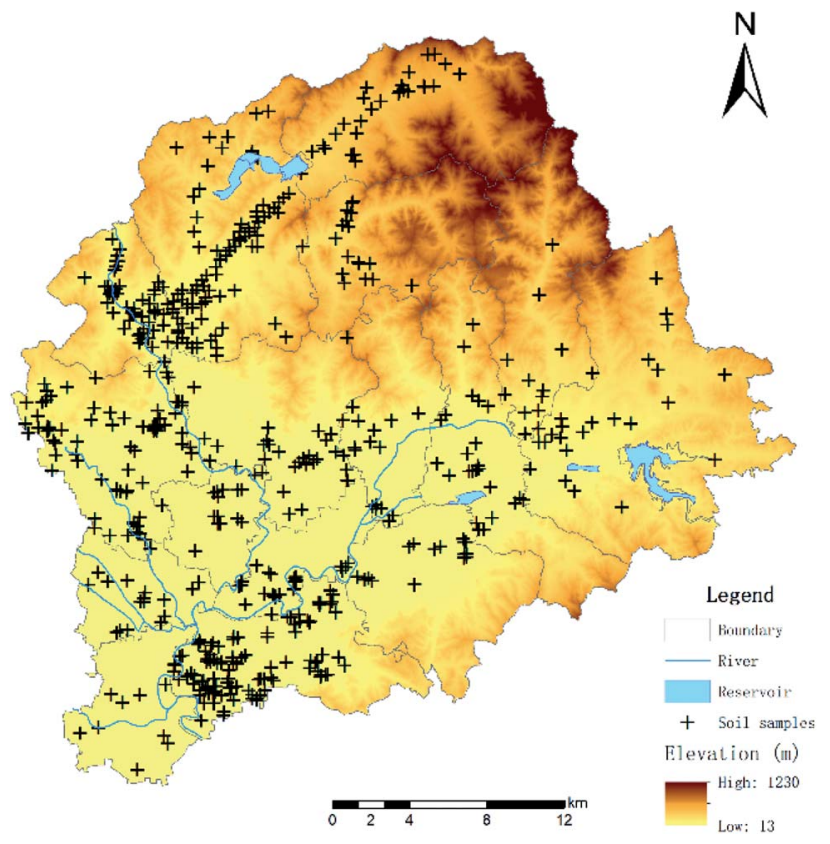

Fig. 1 The sampling sites in the study area.

$25 \mathrm{~cm}$, and about $1 \mathrm{~kg}$ of soil was obtained for each sample using the quartering method. Each sample was packed in a sealed bag and marked before being quickly brought back to the laboratory and stored in a refrigerator at $-20{ }^{\circ} \mathrm{C}$ until analysis.

\subsection{Chemicals and reagents}

Analytical reagent grade supplies of sodium chloride $(\mathrm{NaCl})$, anhydrous magnesium sulfate $\left(\mathrm{MgSO}_{4}\right)$, citric acid, formic acid, dibasic sodium phosphate, and ethylenediaminetetraacetic acid (EDTA) were purchased from the Beijing Chemical Reagent Company (Beijing, PR China). HPLC-grade acetonitrile and methanol were purchased from Fisher Scientific (Pittsburgh, PA, USA). An Aquapro Ultrapure Water System was used to provide ultrapure water. Cleanert $\mathrm{C}_{18}$, primary secondary amine (PSA), mixed anion-exchange (PAX) and strong anion-exchange (SAX) were obtained from Agela Technologies, Tianjin, China.

Forty-seven (47) pesticides standards were purchased from Beijing Beina Chuanglian Biotechnology Institute. Individual stock standard solutions were prepared in acetonitrile and stored at $-20{ }^{\circ} \mathrm{C}$. The mixed working solutions of carbofuran, carbendazim, pymetrozine $\left(10 \mathrm{mg} \mathrm{L}^{-1}\right)$ were prepared in acetonitrile. The other 44 pesticides $\left(100 \mathrm{mg} \mathrm{L}^{-1}\right)$ were prepared in acetonitrile as mixed working solutions.

Standards for 10 antibiotics were purchased from the Beijing Beina Chuanglian Biotechnology Institute. Erythromycin (1000 $\left.\mathrm{mg} \mathrm{L}^{-1}\right)$, roxithromycin $\left(1000 \mathrm{mg} \mathrm{L}^{-1}\right)$, chlortetracycline (10 $\left.\mathrm{mg} \mathrm{L} \mathrm{L}^{-1}\right)$, tetracycline $\left(10 \mathrm{mg} \mathrm{L}^{-1}\right)$, and doxycycline (10 $\mathrm{mg} \mathrm{L}^{-1}$ ) were prepared in acetonitrile as stock standard solutions. Stock standard solutions of the other 5 antibiotics $\left(10 \mathrm{mg} \mathrm{\textrm {L } ^ { - 1 }}\right)$ were prepared in methanol. All stock standard 
solutions were stored at $-20{ }^{\circ} \mathrm{C}$. The concentration of the purchased standard determined the concentration of the working solution. The EDTA-McIlvaine buffer solution was prepared by dissolving $2.8 \mathrm{~g}$ citric acid, $13.9 \mathrm{~g}$ dibasic sodium phosphate, and $8.2 \mathrm{~g}$ EDTA in $200 \mathrm{~mL}$ of water.

\subsection{Pesticides analysis}

A portion (10.0 g) of each soil sample was weighed into a $50 \mathrm{~mL}$ centrifuge tube with $5 \mathrm{~mL}$ water, $10 \mathrm{~mL}$ acetonitrile, and $3 \mathrm{~g}$ $\mathrm{NaCl}$ being added afterwards. Extraction was carried out with a vortex mixer for $2 \mathrm{~min}$ followed by centrifugation for $5 \mathrm{~min}$ at 3800 revolutions per minute $(\mathrm{rpm}) .1 \mathrm{~mL}$ of the supernatant was transferred into a $2 \mathrm{~mL}$ centrifuge tube containing $50 \mathrm{mg}$ of C18. The mixture was vortexed for $30 \mathrm{~s}$ and centrifuged at $10000 \mathrm{rpm}$ for $1 \mathrm{~min}$. After centrifugation, the supernatant was filtered through a $0.22 \mu \mathrm{m}$ membrane into an autosampler vial for HPLC-MS/MS analysis.

\subsection{Antibiotics analysis}

A portion of each soil sample $(2.0 \mathrm{~g})$ was weighed into a $50 \mathrm{~mL}$ centrifuge tube and mixed thoroughly by vortexing for $5 \mathrm{~min}$ with $8 \mathrm{~mL}$ extracting solution (methanol/EDTA-McIlvaine buffer solution, $\mathrm{v} / \mathrm{v}=1 / 1)$. The sample was then centrifuged for $5 \mathrm{~min}$ at $3800 \mathrm{rpm} .1 \mathrm{~mL}$ of the supernatant was filtered through a $0.22 \mu \mathrm{m}$ filter membrane for analysis by HPLC-MS/ MS.

\subsection{HPLC-MS/MS condition}

The HPLC-MS/MS system (Agilent technologies, USA) consisted of a 1200 Series liquid chromatographer coupled to a triple quadrupole mass spectrometer (6410 Triple Quad) equipped with an electrospray ionization interface (ESI). All target compounds were separated using a HPLC reverse-phase C18 column $(50 \mathrm{~mm} \times 2.1 \mathrm{~mm} \times 3.5 \mu \mathrm{m}$, Agilent technologies, USA). The gradient mobile phase consisted of methanol (phase A) and $0.1 \%$ formic acid (phase B). The gradient elution program for the 47 pesticides and 10 antibiotics was shown in ESI (Tables S1 and S2 $\dagger$ ). The injection volume was $5 \mu \mathrm{L}$ and the column temperature was maintained at $30{ }^{\circ} \mathrm{C}$. The total chromatographic run times for the 47 pesticides and 10 antibiotics were $25 \mathrm{~min}$ and $13.5 \mathrm{~min}$, respectively. The HPLC-MS/ MS was performed in multiple-reaction monitoring (MRM) mode and positive ESI mode. The desolvation gas $\left(\mathrm{N}_{2}\right)$ temperature was maintained at $350{ }^{\circ} \mathrm{C}$ with the gas flow being maintained at $8.0 \mathrm{~L} \mathrm{~min}^{-1}$, and the nebulizer pressure being maintained at 35 psi. The optimized parameters of the 47 pesticides and 10 antibiotics are provided in Tables S3 and S4. $\dagger$

\subsection{Date analysis}

Excel 2013 was used for performing all statistical analysis. Spatial distribution of the concentrations of pesticides and antibiotics were plotted by ArcGIS 10.0 (ESRI, Redlands, CA, USA).

\section{Results and discussion}

\subsection{HPLC-MS/MS conditions optimization}

The composition of the mobile phase is an important parameter in adjusting retention time, selectivity, and peak shape in HPLC separation. ${ }^{29}$ Because a large spectrum of analysed compounds has great differences between physicochemical properties and acid-base properties, chromatographic separation using a gradient elution program. ${ }^{25}$ Most target compounds had higher response and sharper peaks using a gradient elution of methanol-water (containing $0.1 \%$ formic acid) system (Tables S1 and S2 $\dagger$ ). The total ion chromatograms (TIC) of 47 pesticides and 10 antibiotics were shown in Fig. 2.

The optimization of MS/MS conditions was performed to obtain maximum sensitivity for each pesticide by introducing individual standard solutions directly into MS/MS. In the present study, all target compounds were both determined in the positive mode (ESI+). MS/MS parameters were optimised such as precursor ion, product ions, fragmentor and collision energy (CE). The values of the MS/MS optimized parameters for each MRM transition were shown in Tables S3 and S4. $\dagger$

\subsection{Sample preparation optimization}

It was especially important to develop a quick, easy, and sensitive method to prepare the samples because of the large number of samples. Since soil contains a large amount of natural organic matter, ${ }^{23}$ extraction and purification procedures are important factors that can affect the results of the analysis.

3.2.1. Sample preparation optimization for the 47 pesticides. As the water content in soil in general is low, it is necessary to add water before pesticide extraction to hydrate the sample and improve the extraction of the more polar pesticides. Acetonitrile is often used as an extraction solvent for multi-residue analysis because it provides higher recoveries, less interference, and fewer co-extracted matrix components than other solvents. ${ }^{30}$ Because some of the 47 pesticides analyzed in this study was acidic and/or highly polar (such as bentazone), a simple study was conducted to compare extraction efficiency between $0.1 \%$ formic acid and water, and to compare extraction efficiency between $\mathrm{NaCl}$ with salting out and $\mathrm{NaCl}$ without salting out. The results showed that a combination of $5 \mathrm{~mL}$ water and $10 \mathrm{~mL}$ acetonitrile with $\mathrm{NaCl}$ salting out provided the best recovery (Fig. S1 $\dagger$ ). PSA and C18 are the most commonly used adsorbents for disperse solid phase extraction (d-SPE) clean-up during residue analysis. PSA is a weak anion exchanger that can remove various organic acids and fatty acids, as well as the target acidic pesticides ${ }^{31}$ and $\mathrm{C} 18$ is used to extract the nonpolar, weak polarity, and medium polar compounds. Since the 47 pesticides analyzed here contain target acidic pesticides, C18 was selected for dSPE clean-up.

3.2.2. Sample preparation optimization for the 10 antibiotics. Extraction of the antibiotics from the soil samples was performed using a methanol/EDTA-McIlvaine buffer solution 

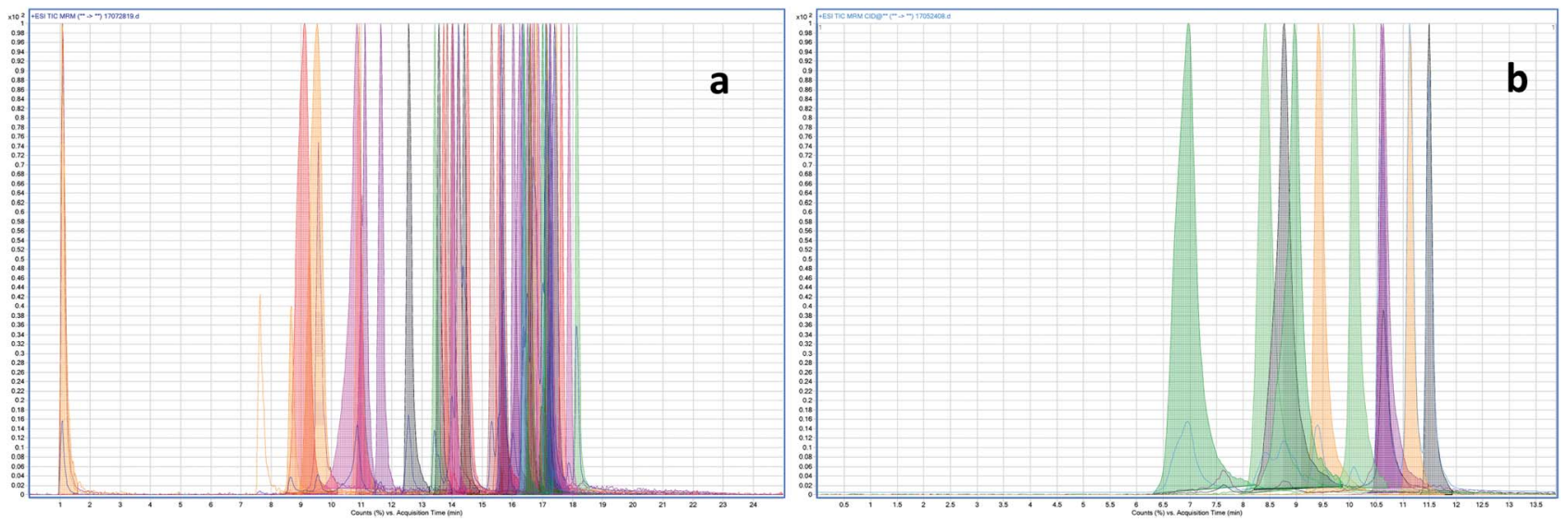

Fig. 2 The total ion chromatograms (TIC) of 47 pesticides (a) and 10 antibiotics (b) at a spiked level of $1 \mathrm{mg} \mathrm{kg}^{-1}$

$(\mathrm{v} / \mathrm{v}=1 / 1)$ based on the study of Chen et al., ${ }^{32}$ and the extraction solvent volume and extraction time were optimized. The results were displayed in Fig. S2 and S3, $\uparrow$ revealing that using $8 \mathrm{~mL}$ of extraction solvent extract 5 minutes returned the best recovery. SAX ${ }^{23}$ and PAX are anion-exchange sorbents that can remove the anions in the soil samples. Due to the low response observed when using SAX in this experiment, PAX was selected for optimization. The recoveries of the 10 antibiotics was low under different PAX dosages (Fig. S4†). Considering that PAX can not only absorb impurities as a cleaner, but also adsorb the target compounds as an adsorbent. Therefore, the PAX adsorbent was eluted with different elution solvents, and the results showed that the recoveries of the 10 antibiotics was still low (Fig. S5†). An experiment was then performed to optimize the activation solvent. The recoveries of antibiotics were performed better after activation with methanol (Fig. S6†). Only two macrolides displayed a lower recovery rate without cleaning-up, while four sulfonamides had a lower recovery rate with methanol-activated cleaning. Furthermore, skipping the cleaning-up step was relatively quick, convenient, and economical. Therefore, the decision was taken not to go through the cleaning-up process.

\subsection{Method validation}

Linear calibration curves were obtained for each of the 47 pesticides and 10 antibiotics by plotting their average peak areas against concentration. A series of matrix standard solutions were diluted using a soil blank matrix extract. The ranges of the seven-point calibration curve for the 47 pesticides and the 10 antibiotics were $0.001-1 \mathrm{mg} \mathrm{L}^{-1}$ and $0.002-0.2 \mathrm{mg} \mathrm{L}^{-1}$, respectively. The calibration curves showed good linearity, with typical correlation coefficients $\left(R^{2}\right)$ between $0.9929-1$. The limit of detection (LOD) was defined as the concentration with a signal-to-noise ratio $(\mathrm{S} / \mathrm{N})$ of $3 .^{33}$ The LODs of the target compounds ranged from $0.01 \mu \mathrm{g} \mathrm{kg}^{-1}$ to $2.00 \mu \mathrm{g} \mathrm{kg}{ }^{-1}$. In order to evaluate the method's accuracy and precision, three to four fortified levels with five duplicates were conducted in the soil samples. The results for the 47 pesticides and 10 antibiotics were listed in Tables S3 and S4. $\dagger$ The fortified recoveries for the majority of the compounds ranged from $70 \%$ to $120 \%$.
Only nicosulfuron (average recovery was 11\%), pymetrozine (45\%), erythromycin (48\%), and roxithromycin (39\%) showed lower recoveries, the results of these compounds were corrected according to the recoveries. Relative standard deviations (RSDs) in all cases were below $20 \%$. The recovery and precision results were satisfactory except for nicosulfuron, pymetrozine, erythromycin, and roxithromycin, according to the residue analysis quality control guide. ${ }^{34}$

\subsection{Pesticide residues in soil samples}

The validated method was applied to detect and quantify residues of the 47 pesticides in 530 soil samples. The total concentrations of the 47 pesticides detected in soil samples ranged from ND to $3.8 \mathrm{mg} \mathrm{kg}^{-1}$. There were high detection rates of pesticides in vegetable plots and orchards, with an average detection rate of $10.1 \%$ for the 12 insecticides, an average detection rate of $9.9 \%$ for the 17 fungicides, and an average detection rate of $3.4 \%$ for the 18 herbicides, indicating that the insecticides and fungicides were used in vegetable fields and orchards were more than herbicides. The detection rates of 37 of the pesticides were low (0-9.2\%) at all sample sites. Among these 37 pesticides, tricyclazole, halosulfuronmethyl, nicosulfuron, pyrazosulfuron-ethyl, and cloransulam-methyl were not detectable. Tricyclazole is a special fungicide for the control of rice blast, however as rice is not grown in the area its absence is perhaps unsurprising. Cloransulam-methyl is used to control broad-leaved weeds in soybean fields, and similarly none of the sampling areas covered soybean fields. Halosulfuron-methyl, nicosulfuron, and pyrazosulfuron-ethyl are all sulfonylurea herbicides that are typically used a low dosage and exhibit a moderate-to-rapid degradation rate in soil. ${ }^{35}$

So far, countries or organizations have not given the risk management and control standards for various pesticides in agricultural soils except exachlorocyclohexanes (HCHs) and dichlor-diphenyltrichloroethanes (DDTs). Therefore, this article referred to the risk screening value $\left(0.1 \mathrm{mg} \mathrm{kg}^{-1}\right)$ of HCHs and DDTs in agricultural land in China, and applies it to the risk assessment of other pesticides. ${ }^{36}$ Risk screening values refer to the value of the main pollutants in the soil 


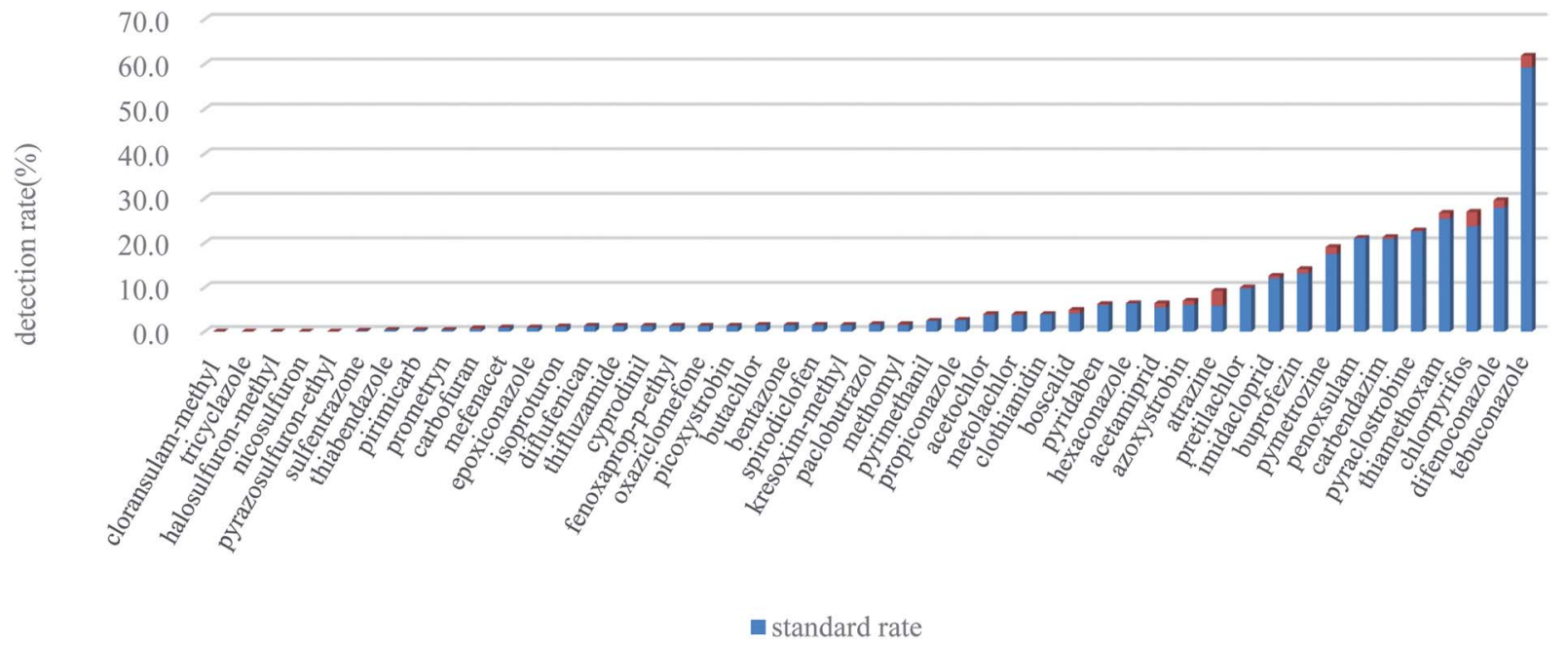

Fig. 3 The detection rate (the sum of standard rate and over standard rate) of 47 pesticides (reference standard is $0.1 \mathrm{mg} \mathrm{kg}^{-1}$ ).

when they may have adverse effects on the quality and safety of agricultural products, crop growth, or the soil's ecological environment. The detection rate (the sum of standard rate and over-standard rate) of these pesticides was showed at Fig. 3. There were 10 pesticides with concentrations exceeding $0.1 \mathrm{mg} \mathrm{kg}^{-1}$, of which atrazine (the over-standard rate was $3.4 \%$ ) should be noted in particular. The ecological risks of atrazine, chlorpyrifos, tebuconazole, difenoconazole, pymetrozine, and thiamethoxam were relatively high in the soil samples, as over $1.0 \%$ of the sample concentrations exceeded $0.1 \mathrm{mg} \mathrm{kg}{ }^{-1}$. The spatial distribution and pollution levels of these six pesticides were shown in Fig. 4. These results showed that more than $60.0 \%$ of the locations where concentrations were above standard levels were in orchards, and the rest were mostly located in vegetable fields. Samples taken from grain fields rarely exceed the standard. These results indicated that the largest volumes of pesticides were used in orchards.

More than $66.7 \%$ of the samples that gave higher than standard atrazine concentrations were located in the same town. A previous study found that atrazine is unexpectedly persistent in soil, ${ }^{37}$ indicating that it can accumulate in farmland due to repeated application, causing high residues. Chlorpyrifos and thiamethoxam are highly effective, broadspectrum, and long-lasting insecticides. Difenoconazole and tebuconazole are highly effective, broad-spectrum, lowtoxicity, and systemic fungicides. ${ }^{38}$ Pymetrozine has been listed as an alternative to highly toxic pesticides in recent years, and exhibits high efficiency, low toxicity, high selectivity, and environmental friendliness, resulting in extensive usage. ${ }^{39}$ Atrazine and chlorpyrifos are listed as endocrine disruptors with moderate-to-high toxicity. ${ }^{40}$ Therefore, it is necessary to strengthen the monitoring of soil environments, to coordinate monitoring of agricultural products, and to improve the awareness of safe pesticide use by local farmers. In principle, measures should be taken for safe utilization. Furthermore, further study is needed on the effects of pesticide mixtures on human health, taking into account possible synergetic interactions at low concentrations. ${ }^{41}$

\subsection{Antibiotics residues in soil samples}

In the 530 soil samples analyzed, the residual levels of the 10 antibiotics were relatively low (ND-951.0 $\mu \mathrm{g} \mathrm{kg}{ }^{-1}$ ). The detection frequencies of the 4 sulfonamides and 2 macrolides were below $0.8 \%$, while the tetracyclines exhibited a high detection rate $(20.9 \%)$. These results are consistent with the findings of a previous study. ${ }^{42}$ The tetracyclines (949.4 $\mu \mathrm{g} \mathrm{kg}^{-1}$ ) had the highest accumulation, followed by macrolides $\left(71.6 \mu \mathrm{g} \mathrm{kg}^{-1}\right)$ and sulfonamides $\left(19.7 \mu \mathrm{g} \mathrm{kg}{ }^{-1}\right)$, and the sulfonamides were rarely detected. The spatial distribution and concentrations of the tetracyclines at all sites were illustrated in Fig. 5. The ecological risk of these four tetracyclines in the soils was relatively high, $2.8 \%$ of the sample concentrations exceeded the ecotoxic effect trigger value $\left(100 \mu \mathrm{g} \mathrm{kg}^{-1}\right)$ setted by the Steering Committee of the Veterinary International Committee on Harmonization. ${ }^{43}$ The results showed that many of the samples exceeding the ecotoxic effect trigger value were located in orchards, indicating that animal manures were most frequently used in orchards. It is necessary to further investigate factors such as the environmental fate of pollutants, plant uptake, and human exposure to antibiotics. Furthermore, the occurrence of antibiotic resistance should not be ruled out even if the measured concentrations of the antibiotics in the soil samples fall below the trigger value of $100 \mu \mathrm{g} \mathrm{kg}^{-1}$ for risk assessment. ${ }^{44}$ Several studies had reported previously that tetracyclines exhibit the highest detection rates, with oxytetracycline exhibiting the highest concentration. ${ }^{43,45,46}$ However, in this study, chlortetracycline showed the highest concentration of the tetracyclines $\left(942.0 \mu \mathrm{g} \mathrm{kg}{ }^{-1}\right.$, oxytetracycline was measured at $338.3 \mu \mathrm{g} \mathrm{kg}^{-1}$, doxycycline at 333.6 $\mu \mathrm{g} \mathrm{kg}^{-1}$ and tetracycline at $139.4 \mu \mathrm{g} \mathrm{kg}{ }^{-1}$ ). This difference may result from the common use of chicken manure and sheep feces in the study area; manure was being used at 

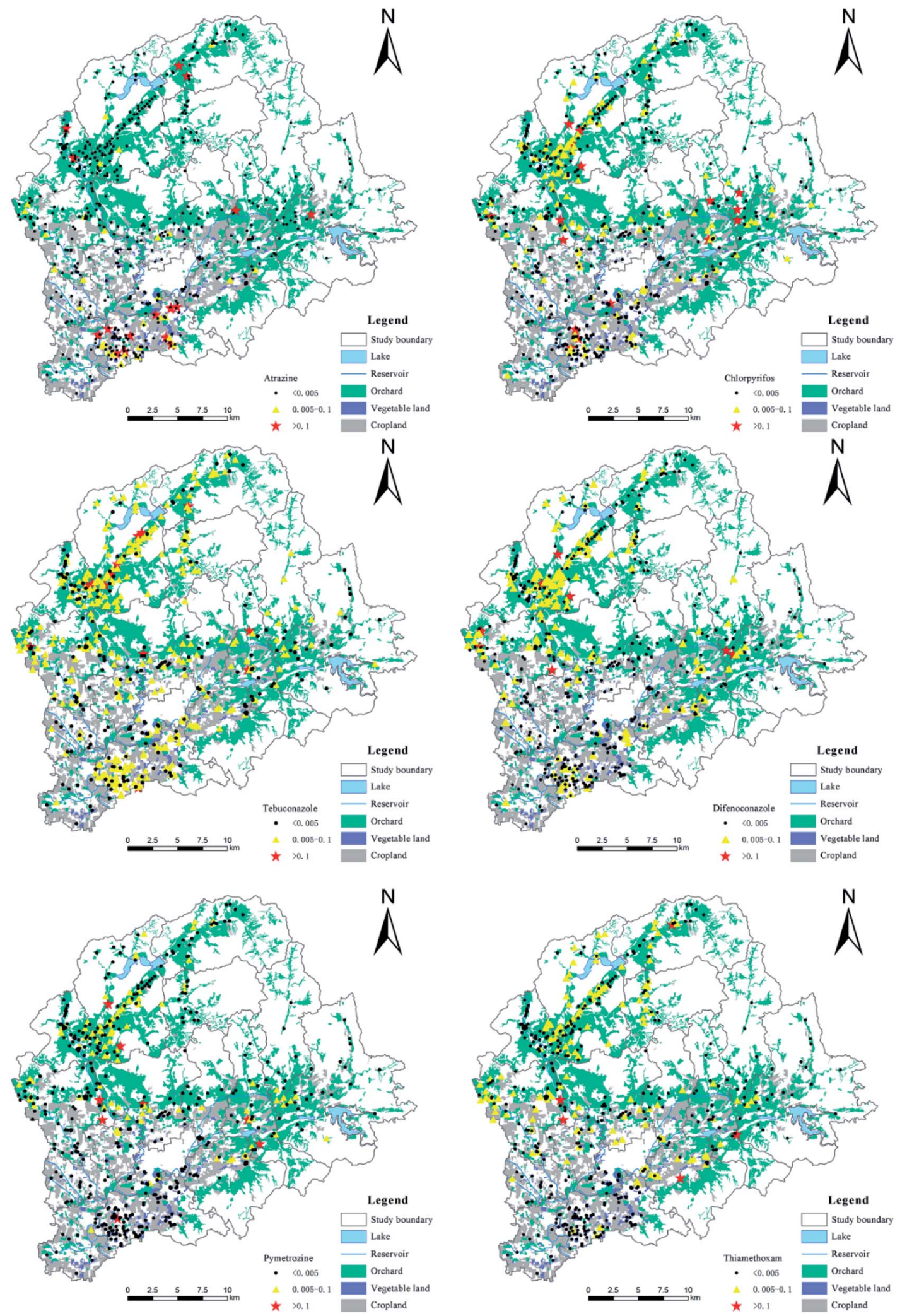

Fig. 4 Spatial distribution and pollution levels of atrazine, chlorpyrifos, tebuconazole, difenoconazole, pymetrozine and thiamethoxam in the studied area.

$40.0 \%$ of the sampling sites, of which $32.3 \%$ featured chicken manure and sheep manure. The maximum predicted halflives of the tetracyclines had been reported as 2.19 years, ${ }^{42}$ indicating that these compounds can accumulate in farmland through the repeated application of biosolids; they may then become persistent in soil. In order to prevent further 


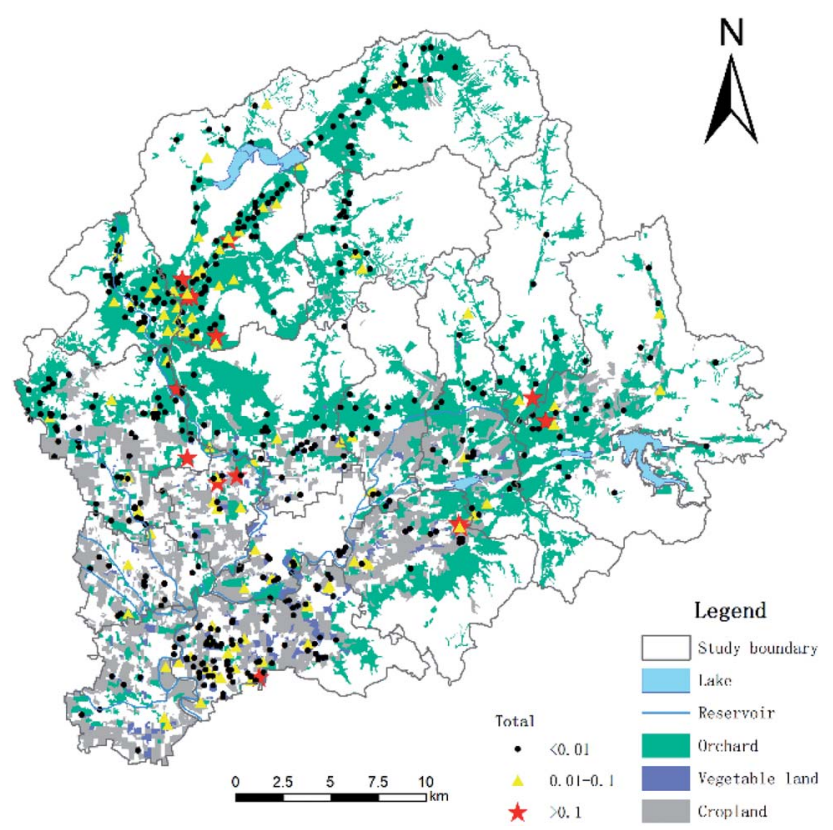

Fig. 5 Spatial distribution and pollution levels of tetracyclines in the studied area.

diffusion of antibiotics, soil amendment with compost can be used to enhance the adsorption of tetracyclines and reduce their mobility, thereby decreasing the environmental risks they pose. ${ }^{47}$

\section{Conclusions}

This study established two analytical methods to separate determine 47 pesticides and 10 antibiotic residues in 530 soil samples collected in a typical farm area in northern China. Total concentrations of 47 pesticides in the soil samples ranged from ND to $3.8 \mathrm{mg} \mathrm{kg}^{-1}$, and total concentrations of 10 antibiotics ranged from ND-951.0 $\mu \mathrm{g} \mathrm{kg}^{-1}$. Atrazine, chlorpyrifos, tebuconazole, difenoconazole, pymetrozine, and thiamethoxam should be noted as over $1.0 \%$ of the sample concentrations exceeded $0.1 \mathrm{mg} \mathrm{kg}^{-1}$. Tetracyclines exhibited a high detection rate (20.9\%), with $2.8 \%$ of the soil samples exhibiting tetracyclines concentrations exceeding $100 \mu \mathrm{g} \mathrm{kg}^{-1}$. These compounds could pose a potential risk. Soil samples from orchards most frequently exhibited concentrations exceeding standards, followed by vegetable plots, grain fields rarely returned concentrations exceeding the standards. These implied that pesticides and organic fertilizers are more frequently used in orchards than other land use types. Furthermore, it should not be ruled out that synergetic interactions effects of pesticide and antibiotics mixtures on human health can occur at low concentrations. In order to decrease the environmental risks, measures should be taken for safe utilization. The monitoring of soil environment should be strengthen and the monitoring of agricultural products should be coordinated.

\section{Conflicts of interest}

There are no conflicts to declare.

\section{Acknowledgements}

This research was supported by the National Key Research and Development Program of China (2016YFD0300801).

\section{References}

1 Y. Yu, Study on Rapid Screening of Pesticides and Antibiotics in Soil, Chinese Academy of Agricultural Sciences, 2016.

2 H. Sun, L. Zhu and D. Zhou, Environ. Sci. Pollut. Res., 2017, 25, 1-3.

3 S. Tao, W. Liu, Y. Li, Y. Yang, Q. Zuo, B. Li and J. Cao, Environ. Sci. Technol., 2008, 42, 8395-8400.

4 Y. Zhong and L. Zhu, Sci. Total Environ., 2013, 444, 177-182.

5 N. Rodríguez-Eugenio, M. McLaughlin and D. Pennock, Soil Pollution: A Hidden Reality, Food and Agriculture Organization of the United Nations, 2018.

6 X. Wan, J. Yang and W. Song, Soil Water Res., 2018, 13, 234242.

7 Y. Teng, J. Wu, S. Lu, Y. Wang, X. Jiao and L. Song, Environ. Int., 2014, 69, 177-199.

8 Food and Agriculture Organization of the United Nations and Intergovernmental Technical Panel on Soils, Status of the World's Soil Resources (SWSR) - Main Report, 2015.

9 Department of environment and conservation: Australia, Assessment levels for soil sediment and water, 2010, https://www.der.wa.gov.au/your-environment/ contaminated-sites/61-contaminated-sites-guidelines.

10 China council for International Cooperation on Environment and Development: China, Special Policy Study on Soil Pollution Management, 2015, http:// www.sfu.ca/china-council/council-documents/councildocuments.html.

11 J. Xu, Y. Zhang, C. Zhou, C. Guo, D. Wang, P. Du, Y. Luo, J. Wan and W. Meng, Sci. Total Environ., 2014, 497, 267-273.

12 M. Grung, Y. Lin, H. Zhang, A. O. Steen, J. Huang, G. Zhang and T. Larssen, Environ. Int., 2015, 81, 87-97.

13 C. Lesueur, M. Gartner, A. Mentler and M. Fuerhacker, Talanta, 2008, 75, 284-293.

14 Q. Q. Zhang, G. G. Ying, C. G. Pan, Y. S. Liu and J. L. Zhao, Environ. Sci. Technol., 2015, 49, 6772-6782.

15 X. Hu, Q. Zhou and Y. Luo, Environ. Pollut., 2010, 158, 29922998.

16 D. H. Wall, U. N. Nielsen and J. Six, Nature, 2015, 528, 69-76.

17 E. Morillo and J. Villaverde, Sci. Total Environ., 2017, 586, 576-597.

18 E. Atuanya and W. Aborisade, Global J. Environ. Sci. Manage., 2017, 3, 287-298.

19 P. A. Blackwell, P. Kay and A. B. Boxall, Chemosphere, 2007, 67, 292-299.

20 N. Homazava, C. Gachet Aquillon, E. Vermeirssen and I. Werner, Int. J. Environ. Anal. Chem., 2014, 94, 1085-1099. 
21 B. Łozowicka, E. Rutkowska and M. Jankowska, Environ. Sci. Pollut. Res., 2017, 24, 7124-7138.

22 X. B. Yang, G. G. Ying and R. S. Kookana, J. Environ. Sci. Health, Part B, 2010, 45, 152-161.

23 S. O'Connor and D. S. Aga, TrAC, Trends Anal. Chem., 2007, 26, 456-465.

24 R. P. Carneiro, F. A. S. Oliveira, F. D. Madureira, G. Silva, W. R. de Souza and R. P. Lopesb, Food Control, 2013, 33, 413-423.

25 T. Kiljanek, A. Niewiadowska, S. Semeniuk, M. Gaweł, M. Borzęcka and A. Posyniak, J. Chromatogr. A, 2016, 1435, 100-114.

26 I. A. Bakar, M. K. Ayub, A. M. Yatim and N. A. Sani, Asian Journal of Food and Agro-Industry, 2010, 3, 328-334.

27 I. Mujic, V. Alibabic, S. Jokic, E. Galijasevic, D. Jukic, D. Sekulja and M. Bajramovic, Pol. J. Environ. Stud., 2011, 20, 719-724.

28 M. Varol and M. R. Sünbül, Environ. Pollut., 2017, 230, 311319.

29 S. O'Connor and D. S. Aga, TrAC, Trends Anal. Chem., 2007, 26, 456-465.

30 G. Chen, P. Cao and R. Liu, Food Chem., 2011, 125, 14061411.

31 X. X. Feng, J. L. Yu, L. X. Pan, G. C. Song and H. Y. Zhang, Int. J. Environ. Res. Public Health, 2016, 13, 534-547.

32 Y. S. Chen, H. B. Zhang, Y. M. Luo and J. Song, Chin. Sci. Bull., 2012, 57, 606-614.

33 X. You, L. Liang and F. M. Liu, Food Chem., 2014, 143, 170174.

34 European Commission, Guidance document on pesticide residue analytical methods, https:/ec.europa.eu/food/sites/ food/files/plant/docs/pesticides_ppp_appproc_guide_res_post-reg-cont-monitor.pdf.

35 J. B. Deng, World Pestic., 2003, 25, 24-29.

36 China's Ministry of Environmental Protection and State Administration for Market Regulation, Soil environmental quality Risk control standard for soil contamination of agricultural land, GB15618-2018, http://kjs.mee.gov.cn/ hjbhbz/bzwb/trhj/trhjzlbz/201807/t20180703_446029.shtml.

37 N. D. Jablonowski, S. Köppchen, D. Hofmann, A. Schäffer and P. Burauel, Environ. Pollut., 2009, 157, 2126-2131.

38 I. S. Kim, L. A. Beaudette, J. H. Shim, J. T. Trevors and T. S. Yong, Plant Soil, 2002, 239, 321-331.

39 J. Sun and B. G. Zhao, World Pestic., 2009, 31, 35-36.

40 S. Zheng, B. Chen, X. Qiu, M. Chen, Z. Ma and X. Yu, Chemosphere, 2016, 144, 1177-1192.

41 A. F. Hernández, T. Parrón, A. M. Tsatsakis, M. Requena, R. Alarcón and O. López-Guarnido, Toxicology, 2013, 307, 136-145.

42 L. Yang, L. Wu, W. Liu, Y. Huang, Y. Luo and P. Christie, Environ. Sci. Pollut. Res., 2016, 25, 104-114.

43 A. Karci and I. A. Balcioğlu, Sci. Total Environ., 2009, 407, 4652-4664.

44 H. Gerd, S. Silke, H. Heinrich and N. Heinz, Anal. Chem., 2002, 74, 1509-1518.

45 X. Li, P. Guo, Y. Shan, Y. Ke, H. Li, Q. Fu, Y. Wang, T. Liu and X. Xia, J. Chromatogr. A, 2017, 1499, 57-64.

46 J. Zilles, T. Shimada, A. Jindal, M. Robert and L. Raskin, Water Environ. Res., 2005, 77, 57-62.

47 L. L. Li, L. D. Huang, C. Renshih, F. Kahang and Y. S. Zhang, Pedosphere, 2010, 20, 807-816. 